\title{
Increasing incidence of Clostridium difficile infections: results from a 5-year retrospective study in a large teaching hospital in the Italian region with the oldest population
}

\author{
C. ALICINO ${ }^{1}$, D. R. GIACOBBE ${ }^{1,2} *$ P. DURANDO ${ }^{1,3}$, D. BELLINA ${ }^{4}$, \\ A. M. DI BELLA ${ }^{4}$, C. PAGANINO ${ }^{1}$, V. DEL BONO ${ }^{2}$, C. VISCOLI $^{1,2}$, \\ G. ICARDI ${ }^{1,4}$ AND A. ORSI ${ }^{1,4}$ \\ ${ }^{1}$ Department of Health Sciences, University of Genoa, Genoa, Italy \\ ${ }^{2}$ Infectious Diseases Unit, IRCCS University Hospital San Martino-IST National Institute for Cancer Research, \\ Genoa, Italy \\ ${ }^{3}$ Occupational Medicine Unit, IRCCS University Hospital San Martino-IST National Institute for Cancer \\ Research, Genoa, Italy \\ ${ }^{4}$ Hygiene and Infection Control Unit, IRCCS University Hospital San Martino-IST National Institute for \\ Cancer Research, Genoa, Italy
}

Received 29 February 2016; Final revision 19 April 2016; Accepted 19 April 2016; first published online 19 May 2016

\section{SUMMARY}

Limited information is available on the incidence of Clostridium difficile infections (CDIs) in Italian hospitals. In this study, we assessed the changes in the incidence of CDI over a 5 -year period in a teaching hospital in Liguria, the Italian region with the oldest population. Secondary endpoints were the development of severe CDI and 30-day mortality. The annual incidence of CDI/10000 patient-days significantly increased from 0.54 in 2010 to 3.04 in $2014\left(\chi^{2}\right.$ for trend, $\left.P<0.001\right)$. The median age of patients with CDI was 81 years. As many as $81 \%$ and $89 \%$ of these patients had comorbid conditions and previous exposure to antibiotics, respectively. In the multivariate analysis of risk factors for severe CDI, previous therapy with histamine 2 blockers and low serum albumin were associated with severe CDI, while diabetes appeared to be protective. In the multivariate model of risk factors for 30-day mortality, high leukocyte count, low serum albumin, and increased serum creatinine were unfavourably associated with outcome. Strict adherence to infection control measures was of utmost importance to counteract the increasing incidence of CDI in our hospital, particularly because of the advanced age of the patients and their very high frequency of chronic conditions and use of antibiotics, which readily predispose them to the development of CDI.

Key words: Clostridium difficile, healthcare-associated infections, hospital-acquired infections, incidence, mortality.

\section{INTRODUCTION}

Clostridium difficile is the major cause of hospitalacquired infectious diarrhoea and one of the most

\footnotetext{
* Author for correspondence: D. R. Giacobbe, MD, IRCCS University Hospital San Martino-IST National Institute for Cancer Research, Infectious Diseases Unit, L. go R. Benzi 10-16132, Genoa, Italy.

(Email: daniele.roberto.giacobbe@gmail.com)
}

common pathogens responsible for healthcare-associated infections [1]. Over the past decades, a marked increase in the incidence of $C$. difficile infections (CDIs) has been reported from different countries and continents [2-4]. In the United States, CDI hospitalizations $/ 10000$ population increased from $3 \cdot 1$ cases in 1996 to $6 \cdot 1$ in 2003 , and from $5 \cdot 5$ cases in 2000 to $11 \cdot 2$ in 2005 [5, 6]. A similar epidemiological picture has been observed in Europe [7-9]. 
In recent years, a relative increase in the number of severe cases of CDI has also been registered, possibly related to the increased use of wide-spectrum antibiotics and the emergence and spread of hypervirulent strains [2, 10-12].

To reduce both the incidence of CDI and the proportion of severe cases the supranational data cited above should be considered together with the detailed epidemiology of every single hospital, aiming at identifying the most cost-effective measures to be used locally. As the first step in this process, we assessed the changes in the incidence of CDI over a 5-year period in a large teaching hospital in Liguria (the Italian region with the oldest population [13]), as well as the risk factors for developing severe disease and for dying within 30 days of infection.

\section{METHODS}

\section{Setting and definitions}

We carried out a retrospective study at IRCCS AOU San Martino-IST, a 1300-bed tertiary adult acutecare teaching hospital in Genoa, Liguria Region, Italy. From 1 January 2010 to 31 December 2014, all patients with hospital-acquired CDI were identified through the hospital laboratory database.

A CDI episode was defined as the presence of at least one unformed stool specimen positive for $C$. diffcile toxin A and/or B (C. Diff Quick Chek complete ${ }^{\circledR}$, Techlab, USA; Alere Medical Co. Ltd, USA), according to the National Health Safety Network (NHSN) definition [14]. For the purpose of the study, recurrences of disease (new episodes occurring within 56 days after the first positive sample) were excluded from the analyses [14]. A CDI episode was defined as hospital-acquired if occurring $>3$ days after hospitalization, or within 28 days after discharge [14].

A CDI episode was classified as severe if fulfilling at least one of the following criteria: (i) death within 14 days after the onset of symptoms; (ii) requirement of intensive care unit (ICU) admission; (iii) requirement of colectomy or other surgery procedures; (iv) intestinal perforation $[15,16]$.

\section{Study endpoints}

The primary endpoint was the incidence of CDI/ 10000 patient-days over the study period. Secondary endpoints were: (i) proportion of positive tested patients; (ii) proportion of severe cases; (iii) development of severe CDI; (iv) 30-day all-cause mortality.

\section{Data collection}

For the computation of the annual incidences of CDI, the overall number of hospital patient-days was obtained from the hospital digital archives of patients' clinical charts.

For the assessment of risk factors for severe disease and mortality, the following data were collected from the medical records of patients with CDI: age; gender; baseline comorbidities (congestive heart failure, myocardial infarction, chronic obstructive pulmonary disease, cerebrovascular accident, solid malignancy, haematological malignancy, diabetes mellitus, chronic renal failure); Charlson comorbidity index score [17]; chronic haemodialysis; previous surgery (within 3 months); previous ICU stay (within 3 months); previous mechanical ventilation (within 3 months); previous therapy with antimicrobials, proton pump inhibitors, and/or histamine 2 (H2) blockers (within 8 weeks before CDI); length of hospital stay before developing CDI; other infections at the time of CDI diagnosis (defined and classified according to CDC definitions [18]); serum haemoglobin, albumin, creatinine, and leukocyte count at the time of CDI diagnosis; type of antimicrobial treatment and complications of CDI (requirement of haemodialysis, requirement of ICU admission, requirement of surgery, intestinal perforation).

\section{Statistical analysis}

Annual CDI incidence rates with their 95\% confidence intervals (CIs) were calculated as the number of events/10000 patient-days. They were also stratified according to the ward where the diagnosis of CDI was made (ICU, medical ward, haemato-oncological ward, rehabilitation ward, surgical ward). A $\chi^{2}$ test for linear trend was used to assess the changes in the annual incidence of CDI in our hospital over the study period, as well as the changes in the proportion of positive tested patients and severe cases.

For the assessment of risk factors for severe CDI and 30-day mortality, continuous variables were dichotomized and cut-off values were determined through receiver-operating characteristic curves. Then, demographic and clinical variables of patients with CDI were compared in univariate analyses by the $\chi^{2}$ test or Fisher's exact test, as appropriate. These tests were performed for both comparisons (patients without severe CDI vs. patients with severe CDI, and survivors vs. non-survivors), all tests were 
two-sided. To assess the independent role of risk factors, variables with a $P$ value $<0.05$ in univariate comparisons were included in two logistic regression models (patients without severe CDI vs. patients with severe CDI, and survivors vs. non-survivors).

Statistical analyses were performed with Epi-Info v. 7.0 (CDC, USA) and JMP v. 10.0 (SAS Institute, USA).

\section{Ethical statement}

The study was performed within the institutional surveillance of healthcare-associated infections and involved the analysis of existing anonymized clinical and laboratory data. An informed consent for the use of anonymized data for scientific purposes is signed by all patients admitted to IRCCS AOU San Martino-IST and included in surveillance databases. The study was approved by the Regional Ethics Committee of Liguria Region.

\section{RESULTS}

During the study period, we identified 388 episodes of hospital-acquired CDI. These episodes occurred in 381 patients, of whom seven experienced at least one novel episode beyond 56 days after the previous CDI (1.8\%). The complete demographic and clinical characteristics of patients at the time of CDI diagnosis are summarized in Tables 1 and 2. Of note, the median age of patients was as high as 81 years [interquartile range (IQR) 74-87] and as many as $81 \%$ and $89 \%$ of the patients had comorbid conditions and previous exposure to antibiotics, respectively.

Table 3 shows that the trend in the annual incidence of CDI/10000 patient-days significantly increased from 0.54 in 2010 to 3.04 in 2014 ( $\chi^{2}$ for linear trend, $P<0.001)$. When the analysis was stratified according to the ward where the CDI diagnosis was made, statistically significant increases were observed in medical, haemato-oncological, and rehabilitation wards. The highest annual incidences of CDI were registered in rehabilitation wards, with a peak of 10.01 episodes $/ 10000$ patient-days in 2013. It should be noted that the proportion of positive tested patients significantly increased over the study period $\left(\chi^{2}\right.$ for trend, $P=0.002)$, while the proportion of severe cases apparently decreased $\left(\chi^{2}\right.$ for trend, $\left.P<0 \cdot 05\right)$.

Seventy-three of $388 \mathrm{CDI}$ episodes met the criteria for severe CDI (18.8\%). Results of the univariate and multivariate analyses of risk factors for severe CDI are shown in Table 4. In the univariate analysis, age $\geqslant 72$ years [odds ratio (OR) $2 \cdot 79,95 \%$ CI $1 \cdot 31$ 6.93, $P=0.007$ ], congestive heart failure (OR 1.98, $95 \%$ CI $1 \cdot 17-3 \cdot 34, P=0 \cdot 01)$, previous mechanical ventilation (OR 2.93, 95\% CI 1.04-7.73, $P=0.04$ ), previous therapy with $\mathrm{H} 2$ blockers (OR $2 \cdot 15,95 \%$ CI $1 \cdot 10-4 \cdot 09, P=0 \cdot 03)$, ward of stay at time of CDI diagnosis, and serum albumin $\leqslant 2.5 \mathrm{~g} / \mathrm{dl}$ (OR 3.30, 95\% CI $1 \cdot 76-6.43, P<0.001)$ were associated with the development of severe CDI, while an intriguing protective role was suggested for diabetes (OR 0.26, $95 \%$ CI $0 \cdot 08-0 \cdot 67, P=0.003)$. In the multivariate analysis, previous therapy with $\mathrm{H} 2$ blockers (OR 2.70, $95 \%$ CI $1 \cdot 13-6 \cdot 38, P=0.03$ ) and serum albumin $\leqslant 2.5 \mathrm{~g} / \mathrm{l}(\mathrm{OR} 2.90,95 \%$ CI 1.44-6.05, $P=0.003)$ remained significantly associated with the development of severe CDI, while diabetes was confirmed as a possible protective factor (OR $0 \cdot 18,95 \%$ CI $0 \cdot 04$ $0 \cdot 57, P=0 \cdot 002$ ).

The all-cause 30-day mortality in patients with CDI was as high as $27 \cdot 8 \%(108 / 388)$. In the univariate analysis of risk factors for mortality, age $\geqslant 72$ years (OR $2 \cdot 52,95 \%$ CI $1 \cdot 34-5.08, P=0.003)$, congestive heart failure (OR 1.92, 95\% CI 1.2-3.05, $P=0 \cdot 006$ ), previous mechanical ventilation (OR 3.47, 95\% CI 1·33-9.33, $P=0.01$ ), ward of stay at the time of CDI diagnosis $(P=0 \cdot 001$, with the highest risk registered for patients hospitalized in ICU wards), other infections at the time of CDI diagnosis (OR 2.30, 95\% CI 1.32-3.99, $P=$ $0 \cdot 004)$, leukocyte count $\geqslant 20$ cells $\times 10^{9} / 1$ (OR $4 \cdot 87$, 95\% CI $2 \cdot 96-8 \cdot 08, P<0 \cdot 001)$, serum albumin $\leqslant 2 \cdot 5$ g/dl (OR 3.04, 95\% CI 1.75-5.39, $P<0 \cdot 001$ ), serum creatinine $\geqslant 1 \cdot 6 \mathrm{mg} / \mathrm{dl}(\mathrm{OR} 3 \cdot 39,95 \%$ CI $2 \cdot 11-5 \cdot 49$, $P<0.001$ ), and requirement of ICU admission (OR $16 \cdot 41,95 \%$ CI $2 \cdot 76-311 \cdot 9, P=0 \cdot 01)$ were unfavourably associated with outcome (see Table 5). Table 5 also shows the results of the related multivariate analysis, which confirmed the following variables as factors significantly and unfavourably associated with outcome: leukocyte count $\geqslant 20$ cells $\times 10^{9} / 1$ (OR $2 \cdot 74,95 \%$ CI $1.39-5.46, \quad P=0.004)$; serum creatinine $\geqslant 1.6 \mathrm{mg} / \mathrm{dl}$ (OR 1.94, 95\% CI 1.0-3.79, $P<0 \cdot 05$ ); serum albumin $\leqslant 2 \cdot 5 \mathrm{~g} / \mathrm{dl}(\mathrm{OR} 2 \cdot 19,95 \%$ CI $1 \cdot 11-4 \cdot 37, P=0 \cdot 02)$.

\section{DISCUSSION}

From 2010 to 2014, we observed an increase of nearly $600 \%$ in the incidence of hospital-acquired CDI in our facility, from 0.54 to $3.04 \mathrm{CDI}$ episodes/10000 patientdays. These episodes mostly occurred in elderly patients, with very high rates of baseline comorbidities and previous antibiotic use. 
Table 1. Demographic, anamnestic and clinical characteristics of the study population with $\mathrm{C}$. difficile infection (CDI)

\begin{tabular}{|c|c|c|}
\hline Patients' features & Patients $(N=388)$ & $\%(95 \% \mathrm{CI})$ \\
\hline \multicolumn{3}{|l|}{ Demographic and anamnestic data } \\
\hline Age, years, median (IQR) & $81(74-87)$ & \\
\hline \multicolumn{3}{|l|}{ Gender } \\
\hline Male & 156 & $40 \cdot 2(35 \cdot 3-45 \cdot 3)$ \\
\hline Female & 232 & $59 \cdot 8(54 \cdot 7-64 \cdot 7)$ \\
\hline Length of hospital stay, days, median (IQR) & $40(25 \cdot 5-64)$ & \\
\hline Length of hospital stay before CDI, days, median (IQR) & $20(11-36)$ & \\
\hline Length of hospital stay after CDI, days, median (IQR) & $15 \cdot 5(7-27 \cdot 8)$ & \\
\hline Charlson comorbidity index score, median (IQR) & $2(1-3)$ & \\
\hline Congestive heart failure & 121 & $31 \cdot 2(26 \cdot 7-36 \cdot 1)$ \\
\hline Myocardial infarction at admission & 10 & $2 \cdot 6(1 \cdot 3-4 \cdot 8)$ \\
\hline Chronic obstructive pulmonary disease & 61 & $15 \cdot 7(12 \cdot 3-19 \cdot 8)$ \\
\hline Cerebrovascular accident & 83 & $21 \cdot 4(17 \cdot 5-25 \cdot 9)$ \\
\hline Solid malignancy & 64 & $16 \cdot 5(13 \cdot 0-20 \cdot 7)$ \\
\hline Haematological malignancy & 21 & $5 \cdot 4(3 \cdot 5-8 \cdot 3)$ \\
\hline Diabetes & 61 & $15 \cdot 7(12 \cdot 3-19 \cdot 8)$ \\
\hline \multicolumn{3}{|l|}{ Renal function } \\
\hline Normal & 294 & $75 \cdot 8(71 \cdot 1-79 \cdot 9)$ \\
\hline Chronic renal insufficiency without dialysis & 81 & $20 \cdot 9(17 \cdot 0-25 \cdot 3)$ \\
\hline End-stage renal insufficiency on dialysis & 13 & $3 \cdot 3(1 \cdot 9-5 \cdot 8)$ \\
\hline Surgery prior to developing CDI & 75 & $19 \cdot 3(15 \cdot 6-23 \cdot 7)$ \\
\hline Abdominal surgery prior to developing CDI & 19 & $4 \cdot 9(3 \cdot 1-7 \cdot 7)$ \\
\hline Mechanical ventilation prior to developing CDI & 18 & $4 \cdot 6(2 \cdot 9-7 \cdot 4)$ \\
\hline Intensive care unit admission prior to developing CDI & 45 & $11 \cdot 6(8 \cdot 7-15 \cdot 3)$ \\
\hline \multicolumn{3}{|l|}{ Medication exposures in the 8 weeks before CDI $(n=385)$} \\
\hline Histamine 2 blocker & 52 & $13 \cdot 5(10 \cdot 3-17 \cdot 4)$ \\
\hline Proton pump inhibitor & 334 & $86 \cdot 8(82 \cdot 9-89 \cdot 9)$ \\
\hline Any antibiotic exposure & 343 & $89 \cdot 1(85 \cdot 4-91 \cdot 9)$ \\
\hline Number of antibiotics, median (IQR) & $2(1-3)$ & \\
\hline Fluoroquinolones & 185 & $48 \cdot 1(43 \cdot 0-53 \cdot 2)$ \\
\hline$\beta$-lactam $/ \beta$-lactamase inhibitors & 152 & $39 \cdot 5(34 \cdot 6-44 \cdot 6)$ \\
\hline 3rd-generation cephalosporins & 129 & $33 \cdot 5(28 \cdot 9-38 \cdot 5)$ \\
\hline Carbapenems & 66 & $17 \cdot 1(13 \cdot 6-21 \cdot 4)$ \\
\hline Glycopeptides & 51 & $13 \cdot 3(10 \cdot 1-17 \cdot 1)$ \\
\hline Metronidazole & 29 & $7 \cdot 5(5 \cdot 2-10 \cdot 8)$ \\
\hline Macrolides & 24 & $6 \cdot 2(4 \cdot 1-9 \cdot 3)$ \\
\hline Aminoglycosides & 12 & $3 \cdot 1(1 \cdot 7-5 \cdot 5)$ \\
\hline Oxazolidinone & 11 & $2 \cdot 9(1 \cdot 5-5 \cdot 2)$ \\
\hline Trimethoprim-sulfamethoxazole & 5 & $1 \cdot 3(0 \cdot 5-3 \cdot 2)$ \\
\hline 4th-generation cephalosporins & 4 & $1 \cdot 0(0 \cdot 3-2 \cdot 8)$ \\
\hline Daptomicin & 3 & $0 \cdot 8(0 \cdot 2-2 \cdot 5)$ \\
\hline Colistin & 1 & $0 \cdot 3(0 \cdot 01-1 \cdot 7)$ \\
\hline Penicillin G & 1 & $0.3(0.01-1 \cdot 7)$ \\
\hline
\end{tabular}

CI, Confidence interval; IQR, interquartile range.

Limited information is available on the incidence of CDI in Italian hospitals [19, 20]. Our results are consistent with those of Di Bella and colleagues, who reported an increased incidence of CDI, from $0 \cdot 3$ cases in 2006 to $2 \cdot 3$ cases/10000 patient-days in 2011 in five hospitals in Rome [19]. Similarly, Bassetti et al. observed an increase in the incidence of CDI from 1.7 cases/10000 patient-days in 2009 to $3 \cdot 0$ cases in 2012 in a teaching hospital in Udine [20]. As in our research, the results of Di Bella et al. and Bassetti et al. relied on enzyme immunoassay (EIA) tests. Importantly, the change in the incidence of $\mathrm{CDI}$ in these studies might have been overestimated because of the increase in the number of tested 
Table 2. Clinical characteristics, therapeutic management and outcomes of C.difficile infections (CDI)

\begin{tabular}{|c|c|c|}
\hline Clinical characteristics and therapeutic management of CDI & Patients $(N=388)$ & $\%(95 \% \mathrm{CI})$ \\
\hline \multicolumn{3}{|l|}{ Ward of admission at onset of CDI } \\
\hline Intensive care & 11 & $2 \cdot 9(1 \cdot 5-5 \cdot 2)$ \\
\hline Medical & 198 & $51 \cdot 0(45 \cdot 9-56 \cdot 1)$ \\
\hline Haemato-oncological & 27 & $7 \cdot 0(4 \cdot 7-10 \cdot 1)$ \\
\hline Rehabilitation & 134 & $34 \cdot 5(29 \cdot 9-39 \cdot 5)$ \\
\hline Surgical & 18 & $4 \cdot 6(2 \cdot 9-7 \cdot 4)$ \\
\hline Infection concomitant to $\mathrm{CDI}^{*}$ & 65 & $16 \cdot 8(13 \cdot 3-20 \cdot 9)$ \\
\hline Bloodstream infection concomitant to CDI & 36 & $9 \cdot 3(6 \cdot 7-12 \cdot 7)$ \\
\hline Leukocyte (cells $\left.\times 10^{9} / 1\right)$, median (IQR) $(n=376)$ & $13 \cdot 8(9-20 \cdot 1)$ & \\
\hline Haemoglobin $(\mathrm{g} / \mathrm{dl})$, median $(\mathrm{IQR})(n=376)$ & $10 \cdot 1(8 \cdot 9-11 \cdot 4)$ & \\
\hline Albumin $(\mathrm{g} / \mathrm{dl})$, median $(\mathrm{IQR})(n=243)$ & $2 \cdot 5(2 \cdot 1-2 \cdot 9)$ & \\
\hline Creatinine (mg/dl), median (IQR) $(n=373)$ & $1 \cdot 1(0 \cdot 7-1 \cdot 8)$ & \\
\hline \multicolumn{3}{|l|}{ Therapeutic management $(n=386)$} \\
\hline No therapy & 15 & $3 \cdot 9(2 \cdot 3-6 \cdot 5)$ \\
\hline Vancomycin (oral) & 261 & $67 \cdot 6(62 \cdot 6-72 \cdot 2)$ \\
\hline Metronidazole (intravenous or oral) & 77 & $19 \cdot 9(16 \cdot 2-24 \cdot 4)$ \\
\hline Vancomycin (oral) and metronidazole (intravenous or oral) & 33 & $8 \cdot 6(6 \cdot 0-11 \cdot 9)$ \\
\hline \multicolumn{3}{|l|}{ Outcome of CDI } \\
\hline Intensive care unit admission & 7 & $1 \cdot 8(0 \cdot 8-3 \cdot 9)$ \\
\hline Abdominal surgery & 1 & $0 \cdot 3(0 \cdot 01-1 \cdot 7)$ \\
\hline Recurrence within 54 days & 30 & $7 \cdot 7(5 \cdot 4-11 \cdot 0)$ \\
\hline Development of severe CDI & 73 & $18 \cdot 8(15 \cdot 2-23 \cdot 1)$ \\
\hline 30-day all-cause mortality & 108 & $27 \cdot 8(23 \cdot 4-32 \cdot 6)$ \\
\hline
\end{tabular}

CI, Confidence interval; IQR, interquartile range.

* Bloodstream $=36(55 \cdot 4 \%)$; urinary tract $=21(32 \cdot 3 \%)$; lower respiratory tract $=7(10 \cdot 7 \%)$; surgical site $=1(1 \cdot 6 \%)$.

patients over years $[19,20]$. Although this bias was also present in our study, the simultaneous increase in the proportion of positive tested patients over the study period seems to confirm the role of $C$. difficile as an important and increasing cause of healthcareassociated diarrhoea. Of note, any change in CDI incidence due to reduced or enhanced adherence to infection-control practices appears unlikely to have occurred, since routine audits to guarantee a high level of compliance were performed in our hospital during the whole study period.

With regard to single departments, it should be noted that in our study the highest peaks in CDI incidence were registered in rehabilitation wards. This possibly occurred because of the high median age, median length of stay, and rate of previous exposure to antimicrobials of patients hospitalized in these wards (they were indeed mostly transferred to the rehabilitation unit after acute care in medical or ICU wards), all well-recognized risk factors for the development of the disease [21]. However, it should also be noted that the overall median age of patients with CDI in the entire hospital was as high as 81 years. To the best of our knowledge, this is the highest median age observed in similar research, and it is probably related to the demographic characteristics of the population in the hospital catchment area [13]. Other important aspects worth reporting are the high frequency of baseline comorbidities $(80.7 \%$ of patients with CDI had at least one chronic condition) and that the overall rate of previous use of antibiotics (mostly fluoroquinolones, $\beta$-lactam $/ \beta$-lactamases inhibitor combinations, and third-generation cephalosporins) was as high as $89 \cdot 1 \%$ in our cohort of CDI patients, among the highest reported in the literature $[20,22,23]$.

As many as $18.8 \%$ of episodes were considered as severe CDI, in line with rates reported by others [24]. Of note, several variables associated with the development of severe CDI (i.e. prior acid suppression, baseline serum albumin $\leqslant 2.5 \mathrm{~g} / \mathrm{dl}$ ) have already been described by other authors, and testify to the role of concomitant medications and nutritional status in influencing the course of the disease, as well as to the possible protective effect exerted by albumin [24, 25]. On the other hand, diabetes was apparently protective against severe CDI in our cohort. This result 


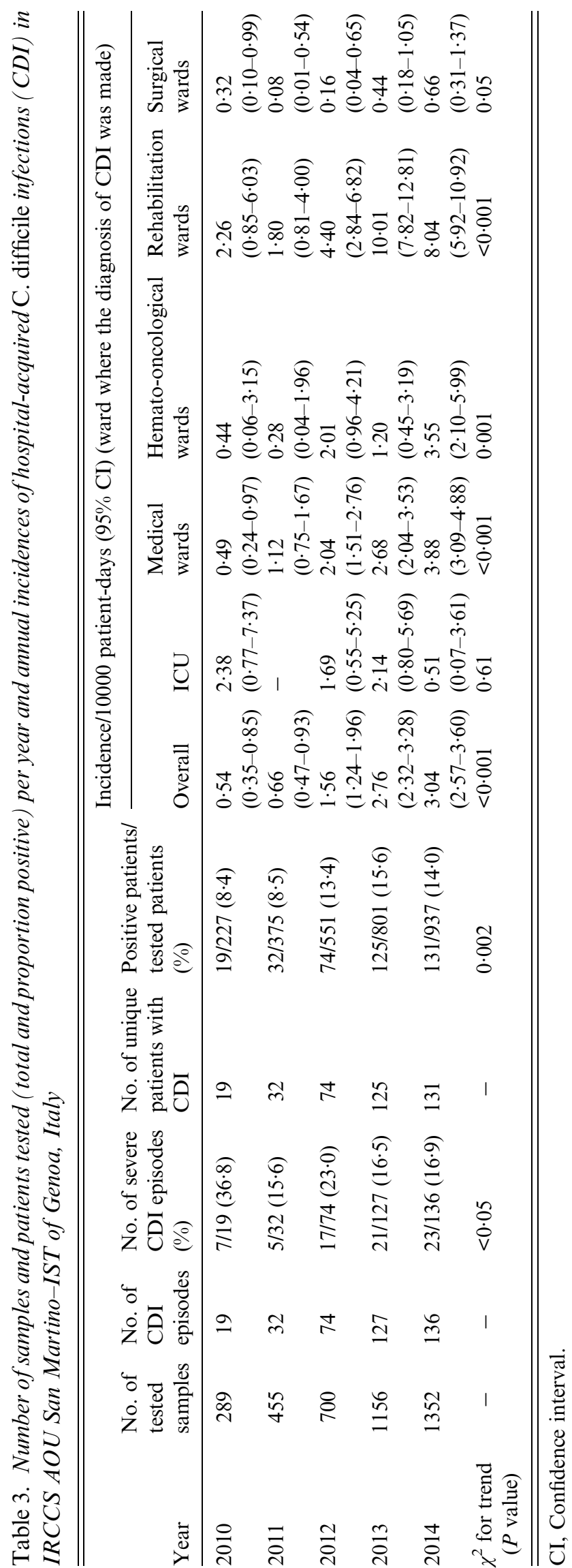

might be explained by the fact that diabetes treatment with metformin might have a protective effect against the development of CDI, according to some literature data [26]. However, this association has not been confirmed by other researchers, who conversely reported a harmful association between diabetes and CDI, thus this warrants further investigation [27].

The 30-day all-cause mortality registered in our study $(27 \cdot 8 \%)$ is consistent with rates reported in the literature [24]. However, we did not register any of the well-known associations between mortality and age, and between mortality and underlying comorbidities (e.g. malignancy, chronic renal failure, etc.) [24]. This is possibly related to the advanced age and the high frequency of chronic conditions in our study population. As regards laboratory variables, we found that a baseline serum leukocyte cell count $\geqslant 20 \times 10^{9} / 1$, a baseline serum albumin level $\leqslant 2.5$ $\mathrm{g} / \mathrm{dl}$, and a serum creatinine level $\geqslant 1.6 \mathrm{mg} / \mathrm{dl}$ were associated with increased mortality, in accord with previous studies [24]. This is consistent with the association of unfavourable outcome of CDI and altered laboratory values, conceivably indicating a severe course of the disease [24].

The present study has some limitations. First, this was a single-centre study, and our results might not be reproducible in other Italian hospitals. In addition, under-reporting possibly occurred in some cases because of the retrospective nature of the study. Another major limitation is the lack of molecular typing data. Indeed, despite an intriguing decrease in the proportion of severe cases observed over the years, the absence of molecular data prevented us from assessing whether this was associated with any possible change in the proportion of hypervirulent strains in our institution during the study period, or if other factors might perhaps better explain these findings. Finally, we were not able to retrospectively conduct a reliable in-depth analysis of possible changes in the type of antibiotics prescribed in our hospital during the study period.

In conclusion, from 2010 to 2014 we observed a marked increase in the incidence of hospital-acquired CDI, highlighting the need for more efficacious preventive interventions, focused on strict adherence to infection control measures and on appropriate antibiotic use. This is of the utmost importance in our hospital, because of the advanced age of our patients and their very high frequency of chronic conditions and use of antibiotics, which readily predispose them to the development of hospital-acquired CDI. 
Table 4. Association between severe C. difficile infection (CDI) and potential independent variables: results of univariate and multivariate logistic regression

\begin{tabular}{|c|c|c|c|c|c|c|}
\hline \multirow[b]{2}{*}{ Variables } & \multirow{2}{*}{$\begin{array}{l}\text { Severe } \\
\text { cases } \\
(N=73) \\
n(\%)\end{array}$} & \multirow{2}{*}{$\begin{array}{l}\text { Non-severe } \\
\text { cases } \\
(N=315) \\
n(\%)\end{array}$} & \multicolumn{2}{|l|}{ Univariate analysis } & \multicolumn{2}{|c|}{ Multivariate analysis } \\
\hline & & & OR $(95 \% \mathrm{CI})$ & $P$ value & OR $(95 \% \mathrm{CI})$ & $P$ value \\
\hline Age $\geqslant 72$ years & $66(90 \cdot 4)$ & $243(77 \cdot 1)$ & $2 \cdot 79(1 \cdot 31-6 \cdot 93)$ & $0 \cdot 007$ & $2 \cdot 11(0 \cdot 80-6 \cdot 28)$ & $0 \cdot 13$ \\
\hline Gender, male & $32(43 \cdot 8)$ & $124(39 \cdot 4)$ & $1 \cdot 20(0 \cdot 72-2 \cdot 00)$ & $0 \cdot 48$ & & \\
\hline $\begin{array}{l}\text { Length of hospital stay before CDI, days, } \\
\text { median (IQR) }\end{array}$ & $19(11-40)$ & $20(11-35)$ & $1 \cdot 0(0 \cdot 99-1 \cdot 01)$ & $0 \cdot 68$ & & \\
\hline Charlson comorbidity index score $\geqslant 2$ & $44(60 \cdot 3)$ & $170(54 \cdot 0)$ & $1 \cdot 29(0 \cdot 77-2 \cdot 19)$ & $0 \cdot 33$ & & \\
\hline Congestive heart failure & $32(43 \cdot 8)$ & $89(28 \cdot 3)$ & $1 \cdot 98(1 \cdot 17-3 \cdot 34)$ & $0 \cdot 01$ & $1.96(0 \cdot 95-4 \cdot 03)$ & $0 \cdot 07$ \\
\hline Myocardial infarction at admission & $4(5 \cdot 5)$ & $6(1 \cdot 9)$ & $2 \cdot 99(0 \cdot 75-10 \cdot 73)$ & $0 \cdot 12$ & & \\
\hline Chronic obstructive pulmonary disease & $10(13 \cdot 7)$ & $51(16 \cdot 2)$ & $0 \cdot 82(0 \cdot 38-1 \cdot 65)$ & $0 \cdot 59$ & & \\
\hline Cerebrovascular accident & $17(23 \cdot 3)$ & $66(21 \cdot 0)$ & $1 \cdot 14(0 \cdot 61-2 \cdot 07)$ & $0 \cdot 66$ & & \\
\hline Solid malignancy & $15(20 \cdot 6)$ & $49(15 \cdot 6)$ & $1 \cdot 40(0 \cdot 71-2 \cdot 63)$ & $0 \cdot 31$ & & \\
\hline Haematological malignancy & $5(6 \cdot 9)$ & $16(5 \cdot 1)$ & $1 \cdot 37(0 \cdot 44-3 \cdot 65)$ & $0 \cdot 56$ & & \\
\hline Diabetes & $4(5 \cdot 5)$ & $57(18 \cdot 1)$ & $0.26(0.08-0.67)$ & $0 \cdot 003$ & $0 \cdot 18(0 \cdot 04-0 \cdot 57)$ & $0 \cdot 002 *$ \\
\hline Renal function & & & & $0 \cdot 54$ & & \\
\hline Normal & $53(72 \cdot 6)$ & $241(79 \cdot 5)$ & Reference & & & \\
\hline $\begin{array}{l}\text { Chronic renal insufficiency without } \\
\text { dialysis }\end{array}$ & $16(21 \cdot 9)$ & $65(20 \cdot 6)$ & $1 \cdot 12(0 \cdot 59-2 \cdot 05)$ & & & \\
\hline End-stage renal insufficiency on dialysis & $4(5 \cdot 5)$ & $9(3 \cdot 0)$ & $2 \cdot 02(0 \cdot 53-6 \cdot 46)$ & & & \\
\hline Surgery prior to developing CDI & $13(17 \cdot 8)$ & $62(19 \cdot 7)$ & $0 \cdot 88(0.44-1.67)$ & $0 \cdot 71$ & & \\
\hline $\begin{array}{l}\text { Abdominal surgery prior to developing } \\
\text { CDI }\end{array}$ & $1(1 \cdot 4)$ & $18(5 \cdot 7)$ & $0 \cdot 23(0 \cdot 01-1 \cdot 14)$ & $0 \cdot 08$ & & \\
\hline $\begin{array}{l}\text { Mechanical ventilation prior to developing } \\
\text { CDI }\end{array}$ & $7(9 \cdot 6)$ & $11(3 \cdot 5)$ & $2.93(1.04-7 \cdot 73)$ & $0 \cdot 04$ & $2 \cdot 25(0 \cdot 40-10 \cdot 58)$ & $0 \cdot 33$ \\
\hline $\begin{array}{l}\text { Intensive care unit admission prior to } \\
\text { developing CDI }\end{array}$ & $12(16 \cdot 4)$ & $33(10 \cdot 5)$ & $1 \cdot 68(0 \cdot 79-3 \cdot 36)$ & $0 \cdot 17$ & & \\
\hline Histamine 2 blocker exposure & $16(21 \cdot 9)$ & $36(11 \cdot 5)$ & $2 \cdot 15(1 \cdot 10-4 \cdot 09)$ & $0 \cdot 03$ & $2 \cdot 70(1 \cdot 13-6 \cdot 38)$ & $0.03^{*}$ \\
\hline Proton pump inhibitor exposure & $62(84 \cdot 9)$ & $272(87 \cdot 2)$ & $0.83(0 \cdot 41-1 \cdot 78)$ & $0 \cdot 62$ & & \\
\hline Any antibiotic exposure & $65(89 \cdot 0)$ & $278(89 \cdot 1)$ & $0.99(0 \cdot 46-2 \cdot 40)$ & $0 \cdot 99$ & & \\
\hline Number of antibiotics, median (IQR) & $2(1-3)$ & $2(1-3)$ & $1 \cdot 05(0 \cdot 84-1 \cdot 30)$ & $0 \cdot 68$ & & \\
\hline Previous fluoroquinolones & $35(48 \cdot 0)$ & $150(48 \cdot 1)$ & $0.99(0 \cdot 60-1 \cdot 66)$ & $0 \cdot 98$ & & \\
\hline $\begin{array}{l}\text { Previous } \beta \text {-lactam } / \beta \text {-lactamase inhibitor } \\
\text { combinations }\end{array}$ & $29(39 \cdot 7)$ & $123(39 \cdot 4)$ & $1 \cdot 01(0 \cdot 60-1 \cdot 70)$ & $0 \cdot 96$ & & \\
\hline Previous 3rd-generation cephalosporins & $22(30 \cdot 1)$ & $107(34 \cdot 3)$ & $0.83(0 \cdot 47-1 \cdot 42)$ & $0 \cdot 50$ & & \\
\hline Previous carbapenems & $16(21 \cdot 9)$ & $50(16 \cdot 0)$ & $1 \cdot 47(0 \cdot 76-2 \cdot 72)$ & $0 \cdot 24$ & & \\
\hline Previous glycopeptides & $9(12 \cdot 3)$ & $42(13 \cdot 5)$ & $0 \cdot 90(0 \cdot 40-1 \cdot 87)$ & $0 \cdot 80$ & & \\
\hline Previous metronidazole & $5(6 \cdot 9)$ & $24(7 \cdot 7)$ & $0 \cdot 88(0 \cdot 29-2 \cdot 22)$ & $0 \cdot 80$ & & \\
\hline Previous macrolides & $6(8 \cdot 2)$ & $18(5 \cdot 8)$ & $1 \cdot 46(0 \cdot 51-3 \cdot 64)$ & $0 \cdot 45$ & & \\
\hline Previous aminoglycosides & $1(1 \cdot 4)$ & $11(3 \cdot 5)$ & $0 \cdot 38(0 \cdot 02-2 \cdot 00)$ & $0 \cdot 38$ & & \\
\hline Previous oxazolidinones & $4(5 \cdot 4)$ & $7(2 \cdot 2)$ & $2 \cdot 53(0 \cdot 65-8 \cdot 60)$ & $0 \cdot 17$ & & \\
\hline Previous trimethoprim/sulfamethoxazole & $1(1 \cdot 4)$ & $4(1 \cdot 3)$ & $1 \cdot 07(0 \cdot 05-7 \cdot 36)$ & $0 \cdot 95$ & & \\
\hline Previous daptomycin & $0(0 \cdot 0)$ & $3(1 \cdot 0)$ & - & & & \\
\hline Ward of admission at onset of CDI & & & & $<0 \cdot 001$ & & $0 \cdot 24$ \\
\hline Surgical & $3(4 \cdot 1)$ & $15(4 \cdot 8)$ & Reference & & Reference & \\
\hline Intensive care & $8(11 \cdot 0)$ & $3(1 \cdot 0)$ & $13 \cdot 33(2 \cdot 44-98 \cdot 99)$ & & $7 \cdot 46(0 \cdot 95-76 \cdot 80)$ & \\
\hline Medical & $44(60 \cdot 2)$ & $154(48 \cdot 9)$ & $1 \cdot 43(0 \cdot 45-6 \cdot 36)$ & & $1 \cdot 61(0 \cdot 42-7 \cdot 90)$ & \\
\hline Haemato-oncological & $4(5 \cdot 5)$ & $23(7 \cdot 3)$ & $0 \cdot 87(0 \cdot 17-4 \cdot 93)$ & & $1 \cdot 24(0 \cdot 18-8 \cdot 32)$ & \\
\hline Rehabilitation & $14(19 \cdot 2)$ & $120(38 \cdot 1)$ & $0 \cdot 58(0 \cdot 17-2 \cdot 73)$ & & $1 \cdot 06(0 \cdot 23-5 \cdot 77)$ & \\
\hline Infection concomitant to CDI & $18(24 \cdot 7)$ & $47(14 \cdot 9)$ & $1 \cdot 87(0 \cdot 99-3 \cdot 41)$ & $0 \cdot 05$ & & \\
\hline Bloodstream infection concomitant to CDI & $9(12 \cdot 3)$ & $27(8 \cdot 6)$ & $1 \cdot 50(0 \cdot 64-3 \cdot 23)$ & $0 \cdot 33$ & & \\
\hline Haemoglobin $\leqslant 10 \cdot 0 \mathrm{~g} / \mathrm{dl}$ & $41(56 \cdot 2)$ & $138(45 \cdot 5)$ & $1 \cdot 53(0 \cdot 92-2 \cdot 58)$ & $0 \cdot 10$ & & \\
\hline Albumin $\leqslant 2.5 \mathrm{~g} / \mathrm{dl}$ & $42(72 \cdot 4)$ & $82(44 \cdot 3)$ & $3 \cdot 30(1 \cdot 76-6 \cdot 43)$ & $<0 \cdot 001$ & $2 \cdot 90(1 \cdot 44-6 \cdot 05)$ & $0 \cdot 003^{*}$ \\
\hline
\end{tabular}

OR, Odds ratio; CI, confidence interval; IQR, interquartile range.

* Statistically significant $(P<0 \cdot 05)$. 
Table 5. Association between 30-day all-cause mortality of C. difficile infection (CDI) and potential independent variables: results of univariate and multivariate logistic regression

\begin{tabular}{|c|c|c|c|c|c|c|}
\hline \multirow[b]{2}{*}{ Variables } & \multirow{2}{*}{$\begin{array}{l}\text { Survivors } \\
(N=280) \\
n(\%)\end{array}$} & \multirow{2}{*}{$\begin{array}{l}\text { Non-survivors } \\
(\mathrm{N}=108) \\
n(\%)\end{array}$} & \multicolumn{2}{|l|}{ Univariate analysis } & \multicolumn{2}{|c|}{ Multivariate analysis } \\
\hline & & & OR $(95 \% \mathrm{CI})$ & $P$ value & OR $(95 \% \mathrm{CI})$ & $P$ value \\
\hline Age $\geqslant 72$ years & $213(76 \cdot 1)$ & $96(88 \cdot 9)$ & $2 \cdot 52(1 \cdot 34-5 \cdot 08)$ & $0 \cdot 003$ & $2 \cdot 27(0 \cdot 92-6 \cdot 04)$ & $0 \cdot 08$ \\
\hline Gender, male & $111(39 \cdot 6)$ & $45(41 \cdot 7)$ & $1 \cdot 09(0 \cdot 69-1 \cdot 71)$ & $0 \cdot 72$ & & \\
\hline $\begin{array}{l}\text { Length of hospital stay before CDI, } \\
\text { days, median (IQR) }\end{array}$ & $20(11-36)$ & $19(11-39)$ & $1 \cdot 00(0 \cdot 99-1 \cdot 01)$ & $0 \cdot 65$ & & \\
\hline $\begin{array}{l}\text { Charlson comorbidity index score } \\
\geqslant 2\end{array}$ & $146(52 \cdot 1)$ & $68(63 \cdot 0)$ & $1 \cdot 56(0.99-2 \cdot 47)$ & $0 \cdot 06$ & & \\
\hline Congestive heart failure & $76(27 \cdot 1)$ & $45(41 \cdot 7)$ & $1 \cdot 92(1 \cdot 2-3 \cdot 05)$ & $0 \cdot 006$ & $1 \cdot 48(0 \cdot 73-3 \cdot 01)$ & $0 \cdot 27$ \\
\hline Myocardial infarction at admission & $6(2 \cdot 1)$ & $4(3 \cdot 7)$ & $1 \cdot 76(0 \cdot 44-6 \cdot 27)$ & $0 \cdot 40$ & & \\
\hline $\begin{array}{l}\text { Chronic obstructive pulmonary } \\
\text { disease }\end{array}$ & $44(15 \cdot 7)$ & $17(15 \cdot 7)$ & $1 \cdot 00(0 \cdot 53-1 \cdot 81)$ & $0 \cdot 99$ & & \\
\hline Cerebrovascular accident & $61(21 \cdot 8)$ & $22(20 \cdot 4)$ & $0 \cdot 92(0 \cdot 52-1 \cdot 57)$ & $0 \cdot 76$ & & \\
\hline Solid malignancy & $43(15 \cdot 4)$ & $21(19 \cdot 4)$ & $1 \cdot 33(0 \cdot 74-2 \cdot 35)$ & $0 \cdot 34$ & & \\
\hline Haematological malignancy & $13(4 \cdot 6)$ & $8(7 \cdot 4)$ & $1 \cdot 64(0 \cdot 63-4 \cdot 02)$ & $0 \cdot 30$ & & \\
\hline Diabetes & $47(16 \cdot 8)$ & $14(13 \cdot 0)$ & $0 \cdot 74(0 \cdot 38-1 \cdot 37)$ & $0 \cdot 35$ & & \\
\hline Renal function & & & & $0 \cdot 11$ & & \\
\hline Normal & $217(77 \cdot 5)$ & $77(71 \cdot 3)$ & Reference & & & \\
\hline $\begin{array}{l}\text { Chronic renal insufficiency } \\
\text { without dialysis }\end{array}$ & $57(20 \cdot 4)$ & $24(22 \cdot 2)$ & $1 \cdot 19(0 \cdot 68-2 \cdot 02)$ & & & \\
\hline $\begin{array}{l}\text { End-stage renal insufficiency on } \\
\text { dialysis }\end{array}$ & $6(2 \cdot 1)$ & $7(6 \cdot 5)$ & $3 \cdot 29(1 \cdot 06-10 \cdot 50)$ & & & \\
\hline Previous surgery & $56(20 \cdot 0)$ & $19(17 \cdot 6)$ & $0 \cdot 85(0 \cdot 47-1 \cdot 50)$ & $0 \cdot 59$ & & \\
\hline Previous abdominal surgery & $17(6 \cdot 1)$ & $2(1 \cdot 9)$ & $0 \cdot 29(0 \cdot 05-1 \cdot 04)$ & $0 \cdot 06$ & & \\
\hline Previous mechanical ventilation & $8(2 \cdot 9)$ & $10(9 \cdot 3)$ & $3 \cdot 47(1 \cdot 33-9 \cdot 33)$ & $0 \cdot 01$ & $4 \cdot 83(0 \cdot 92-25 \cdot 19)$ & $0 \cdot 06$ \\
\hline Previous ICU admission & $27(9 \cdot 6)$ & $18(16 \cdot 7)$ & $1 \cdot 87(0 \cdot 97-3 \cdot 54)$ & $0 \cdot 06$ & & \\
\hline Histamine 2 blocker exposure & $32(11 \cdot 6)$ & $20(18 \cdot 5)$ & $1 \cdot 74(0 \cdot 93-3 \cdot 18)$ & $0 \cdot 08$ & & \\
\hline Proton pump inhibitor exposure & $243(87 \cdot 7)$ & $91(84 \cdot 2)$ & $0 \cdot 75(0 \cdot 40-1 \cdot 43)$ & $0 \cdot 37$ & & \\
\hline Any previous antibiotic exposure & $245(88 \cdot 5)$ & $98(90 \cdot 7)$ & $1 \cdot 28(0 \cdot 63-2 \cdot 84)$ & $0 \cdot 51$ & & \\
\hline $\begin{array}{l}\text { Number of antibiotics, median } \\
\text { (IQR) }\end{array}$ & $2(1-3)$ & $2(1-3)$ & $1 \cdot 12(0 \cdot 93-1 \cdot 35)$ & $0 \cdot 24$ & & \\
\hline Previous fluoroquinolones & $135(48 \cdot 7)$ & $50(46 \cdot 3)$ & $0 \cdot 91(0 \cdot 58-1 \cdot 42)$ & $0 \cdot 67$ & & \\
\hline $\begin{array}{l}\text { Previous } \beta \text {-lactam } / \beta \text {-lactamase } \\
\text { inhibitor combinations }\end{array}$ & $108(39 \cdot 0)$ & $44(40 \cdot 7)$ & $1 \cdot 08(0 \cdot 68-1 \cdot 69)$ & $0 \cdot 75$ & & \\
\hline $\begin{array}{l}\text { Previous 3rd-generation } \\
\text { cephalosporins }\end{array}$ & $91(32 \cdot 9)$ & $38(35 \cdot 2)$ & $1 \cdot 11(0 \cdot 69-1 \cdot 77)$ & $0 \cdot 66$ & & \\
\hline Previous carbapenems & $43(15 \cdot 5)$ & $23(21 \cdot 3)$ & $1 \cdot 47(0 \cdot 83-2 \cdot 57)$ & $0 \cdot 18$ & & \\
\hline Previous glycopeptides & $37(13 \cdot 4)$ & $14(13 \cdot 0)$ & $0 \cdot 97(0 \cdot 49-1 \cdot 83)$ & $0 \cdot 92$ & & \\
\hline Previous metronidazole & $21(7 \cdot 6)$ & $8(7 \cdot 4)$ & $0 \cdot 98(0 \cdot 39-2 \cdot 19)$ & $0 \cdot 95$ & & \\
\hline Previous macrolides & $15(5 \cdot 4)$ & $9(8 \cdot 3)$ & $1.59(0 \cdot 65-3 \cdot 69)$ & $0 \cdot 30$ & & \\
\hline Previous aminoglycosides & $9(3 \cdot 3)$ & $3(2 \cdot 8)$ & $0 \cdot 85(0 \cdot 19-2 \cdot 92)$ & $0 \cdot 80$ & & \\
\hline Previous oxazolidinones & $6(2 \cdot 2)$ & $5(4 \cdot 6)$ & $2 \cdot 19(0 \cdot 62-7 \cdot 43)$ & $0 \cdot 21$ & & \\
\hline $\begin{array}{l}\text { Previous trimethoprim/ } \\
\text { sulfamethoxazole }\end{array}$ & $3(1 \cdot 1)$ & $2(1 \cdot 9)$ & $1 \cdot 72(0 \cdot 22-10 \cdot 53)$ & $0 \cdot 57$ & & \\
\hline Previous daptomycin & $1(0 \cdot 4)$ & $2(1 \cdot 9)$ & $5 \cdot 20(0 \cdot 49-112 \cdot 7)$ & $0 \cdot 16$ & & \\
\hline Ward of admission at onset of CDI & & & & $0 \cdot 001$ & & $0 \cdot 26$ \\
\hline Surgical & $15(5 \cdot 4)$ & $3(2 \cdot 8)$ & Reference & & Reference & \\
\hline Intensive care & $3(1 \cdot 1)$ & $8(7 \cdot 4)$ & $13 \cdot 33(2 \cdot 44-98 \cdot 99)$ & & $6 \cdot 17(0 \cdot 59-86 \cdot 76)$ & \\
\hline Medical & $134(47 \cdot 9)$ & $64(59 \cdot 2)$ & $2 \cdot 39(0 \cdot 75-10 \cdot 57)$ & & $4.59(0.97-34.92)$ & \\
\hline Haemato-oncological & $20(7 \cdot 1)$ & $7(6 \cdot 5)$ & $1 \cdot 75(0 \cdot 41-9 \cdot 17)$ & & $8 \cdot 27(1 \cdot 21-80 \cdot 39)$ & \\
\hline Rehabilitation & $108(38 \cdot 6)$ & $26(24 \cdot 1)$ & $1 \cdot 20(0 \cdot 36-5 \cdot 47)$ & & $4 \cdot 14(0 \cdot 76-34 \cdot 55)$ & \\
\hline $\begin{array}{l}\text { Intensive care unit admission after } \\
\text { CDI diagnosis }\end{array}$ & $1(0 \cdot 4)$ & $6(5 \cdot 6)$ & $16 \cdot 41(2 \cdot 76-311 \cdot 9)$ & $0 \cdot 001$ & $9 \cdot 07(0.92-256 \cdot 79)$ & $0 \cdot 06$ \\
\hline Infection concomitant to CDI & $37(13 \cdot 2)$ & $28(25 \cdot 9)$ & $2 \cdot 30(1 \cdot 32-3 \cdot 99)$ & $0 \cdot 004$ & $2 \cdot 15(0 \cdot 97-4 \cdot 78)$ & $0 \cdot 06$ \\
\hline
\end{tabular}


Table 5 (cont.)

\begin{tabular}{|c|c|c|c|c|c|c|}
\hline \multirow[b]{2}{*}{ Variables } & \multirow{2}{*}{$\begin{array}{l}\text { Survivors } \\
(N=280) \\
n(\%)\end{array}$} & \multirow{2}{*}{$\begin{array}{l}\text { Non-survivors } \\
(\mathrm{N}=108) \\
n(\%)\end{array}$} & \multicolumn{2}{|c|}{ Univariate analysis } & \multicolumn{2}{|c|}{ Multivariate analysis } \\
\hline & & & OR $(95 \% \mathrm{CI})$ & $P$ value & OR $(95 \% \mathrm{CI})$ & $P$ value \\
\hline $\begin{array}{l}\text { Bloodstream infection concomitant } \\
\text { to CDI }\end{array}$ & $21(7 \cdot 5)$ & $15(13 \cdot 9)$ & $1.99(0.97-4.0)$ & $0 \cdot 06$ & & \\
\hline Leukocyte count $\geqslant 20$ cells $\times 10^{9} / 1$ & $44(16 \cdot 2)$ & $51(48 \cdot 6)$ & $4 \cdot 87(2 \cdot 96-8 \cdot 08)$ & $<0.001$ & $2 \cdot 74(1 \cdot 39-5 \cdot 46)$ & $0 \cdot 004 *$ \\
\hline Haemoglobin $\leqslant 10 \cdot 0 \mathrm{~g} / \mathrm{dl}$ & $123(45 \cdot 4)$ & $56(53 \cdot 3)$ & $1 \cdot 38(0 \cdot 88-2 \cdot 17)$ & $0 \cdot 17$ & & \\
\hline Albumin $\leqslant 2.5 \mathrm{~g} / \mathrm{dl}$ & $67(41 \cdot 9)$ & $57(68 \cdot 7)$ & $3 \cdot 04(1 \cdot 75-5 \cdot 39)$ & $<0.001$ & $2 \cdot 19(1 \cdot 11-4 \cdot 37)$ & $0 \cdot 02 *$ \\
\hline Creatinine $\geqslant 1.6 \mathrm{mg} / \mathrm{dl}$ & $59(22 \cdot 1)$ & $52(49 \cdot 1)$ & $3 \cdot 39(2 \cdot 11-5 \cdot 49)$ & $<0.001$ & $1.94(1 \cdot 0-3 \cdot 79)$ & $0 \cdot 05^{*}$ \\
\hline Therapeutic management & & & & $0 \cdot 02$ & & $0 \cdot 76$ \\
\hline No therapy & $6(2 \cdot 2)$ & $9(8 \cdot 3)$ & Reference & & Reference & \\
\hline Vancomycin (oral) & $197(70 \cdot 9)$ & $64(59 \cdot 3)$ & $0 \cdot 22(0 \cdot 07-0 \cdot 62)$ & & $0 \cdot 89(0 \cdot 23-3 \cdot 4)$ & \\
\hline $\begin{array}{l}\text { Metronidazole (intravenous or } \\
\text { oral) }\end{array}$ & $51(18 \cdot 4)$ & $26(24 \cdot 1)$ & $0 \cdot 34(0 \cdot 10-1 \cdot 04)$ & & $1 \cdot 41(0 \cdot 32-6 \cdot 29)$ & \\
\hline $\begin{array}{l}\text { Vancomycin (oral) and } \\
\text { metronidazole (intravenous or oral) }\end{array}$ & $24(8 \cdot 6)$ & $9(8 \cdot 3)$ & $0 \cdot 25(0 \cdot 07-0 \cdot 88)$ & & $0 \cdot 85(0 \cdot 16-4 \cdot 4)$ & \\
\hline
\end{tabular}

OR, Odds ratio; CI, confidence interval; IQR, interquartile range.

* Statistically significant $(P<0 \cdot 05)$.

\section{ACKNOWLEDGEMENTS}

The authors thank Monica Zacconi for assistance with data collection.

\section{DECLARATION OF INTEREST}

None.

\section{REFERENCES}

1. Rupnik M, Wilcox MH, Gerding DN. Clostridium difficile infection: new developments in epidemiology and pathogenesis. Nature Reviews Microbiology 2009; 7: 526-536.

2. Freeman J, et al. The changing epidemiology of Clostridium difficile infections. Clinical Microbiology Reviews 2010; 23: 529-549.

3. Johnson S. Changing epidemiology of Clostridium difficile and emergence of new virulent strains. Clinical Infectious Diseases 2014; 58: 1731-1733.

4. Lessa FC, Gould CV, McDonald LC. Current status of Clostridium difficile infection epidemiology. Clinical Infectious Diseases 2012; 55: s65-70.

5. McDonald LC, Owings M, Jernigan DB. Clostridium difficile infection in patients discharged from US shortstay hospitals, 1996-2003. Emerging Infectious Diseases 2006; 12: 409-115.

6. Zilberberg MD, Shorr AF, Kollef MH. Increase in adult Clostridium difficile-related hospitalizations and casefatality rate, United States, 2000-2005. Emerging Infectious Diseases 2008; 14: 929-931.

7. Asensio A, et al. Increasing rates in Clostridium difficile infection (CDI) among hospitalised patients, Spain 1999-2007. Eurosurveillance 2008; 13: 18943.
8. Bauer MP, et al. Clostridium difficile infection in Europe: a hospital-based survey. Lancet 2011; 377: 63-73.

9. Burckhardt F, et al. Clostridium difficile surveillance trends, Saxony, Germany. Emerging Infectious Diseases 2008; 14: 691-692.

10. McDonald LC, et al. An epidemic, toxin gene-variant strain of Clostridium difficile. New England Journal of Medicine 2005; 353: 2433-2441.

11. Loo VG, et al. A predominantly clonal multiinstitutional outbreak of Clostridium difficile-associated diarrhea with high morbidity and mortality. New England Journal of Medicine 2005; 353: 2442-2449.

12. Kuijper EJ, et al. Clostridium difficile ribotype 027, toxinotype III, the Netherlands. Emerging Infectious Diseases 2006; 12: 827-830.

13. National Institute of Statistics (Istituto Nazionale di Statistica, ISTAT). 'Noi Italia. 100 statistics to understand the country we live in' (http://noi-italia2015.istat. it/index.php?id=6\&user_100ind_pi $1 \% 5$ Buid_categoria $\%$ $5 \mathrm{D}=03 \& \mathrm{~L}=0 \& \mathrm{cHash}=\mathrm{a} 887 \mathrm{dc} 686 \mathrm{dbc} 48407 \mathrm{e} 54196 \mathrm{f} 84 \mathrm{eb}$ 2ede). Accessed 19 April 2016.

14. Centers for Disease Control and Prevention. National Health Safety Network multidrug-resistant organism and Clostridium difficile infection (MDRO/CDI) module (http://www.cdc.gov/nhsn/PDFs/pscManual/12psc MDRO_CDADcurrent.pdf). Accessed 19 April 2016.

15. Sailhamer EA, et al. Fulminant Clostridium difficile colitis: patterns of care and predictors of mortality. Archives of Surgery 2009; 144: 433-439.

16. Debast SB, Bauer MP, Kuijper EJ. Committee. European Society of Clinical Microbiology and Infectious Diseases (ESCMID): update of the treatment guidance document for Clostridium difficile infection (CDI). Clinical Microbiology and Infection 2013; 20 (Suppl. 2): 1-26.

17. Charlson ME, et al. A new method of classifying prognostic comorbidity in longitudinal studies: development 
and validation. Journal of Chronic Diseases 1987; 40: 373-383.

18. European Centre for Disease Prevention and Control. Point prevalence survey of healthcareassociated infections and antimicrobial use in European acute care hospitals-protocol version 4.3. Stockholm: ECDC; 2012 (http://ecdc.europa.eu/en/publications/Publications/0512TED-PPS-HAI-antimicrobial-use-protocol.pdf). Accessed 19 April 2016.

19. Di Bella S, et al. Clostridium difficile infection in Italian urban hospitals: data from 2006 through 2011. BMC Infectious Diseases 2013; 13: 146.

20. Bassetti M, et al. Epidemiology and predictors of recurrence of Clostridium difficile infection in a North Italian tertiary care hospital. Journal of Gastrointestinal and Liver Disease 2014; 23: 459-460.

21. Evans CT, Safdar N. Current trends in the epidemiology and outcomes of Clostridium difficile infection. Clinical Infectious Diseases 2015; 60: S66-71.

22. Honda $\mathbf{H}$, et al. Incidence and mortality associated with Clostridium difficile infection at a Japanese tertiary care center. Anaerobe 2014; 25: 5-10.
23. Rodríguez-Pardo D, et al. Epidemiology of Clostridium difficile infection and risk factors for unfavorable clinical outcomes: results of a hospital-based study in Barcelona, Spain. Journal of Clinical Microbiology 2013; 51: 1465-1473.

24. Abou Chakra CN, et al. Risk factors for recurrence, complications and mortality in Clostridium difficile infection: a systematic review. PLoS ONE 2014; 9: e98400.

25. Di Bella S, et al. The protective role of albumin in Clostridium difficile infection: a step toward solving the puzzle. Infection Control and Hospital Epidemiology 2015; 36: $1478-1479$.

26. Eliakim-Raz N, et al. Predicting Clostridium difficile infection in diabetic patients and the effect of metformin therapy: a retrospective, case-control study. European Journal of Clinical Microbiology and Infectious Diseases 2015; 34: 1201-1205.

27. Wenisch JM, et al. Hospital-acquired Clostridium difficile infection: determinants for severe disease. European Journal of Clinical Microbiology and Infectious Diseases 2012; 31: 1923-1930. 